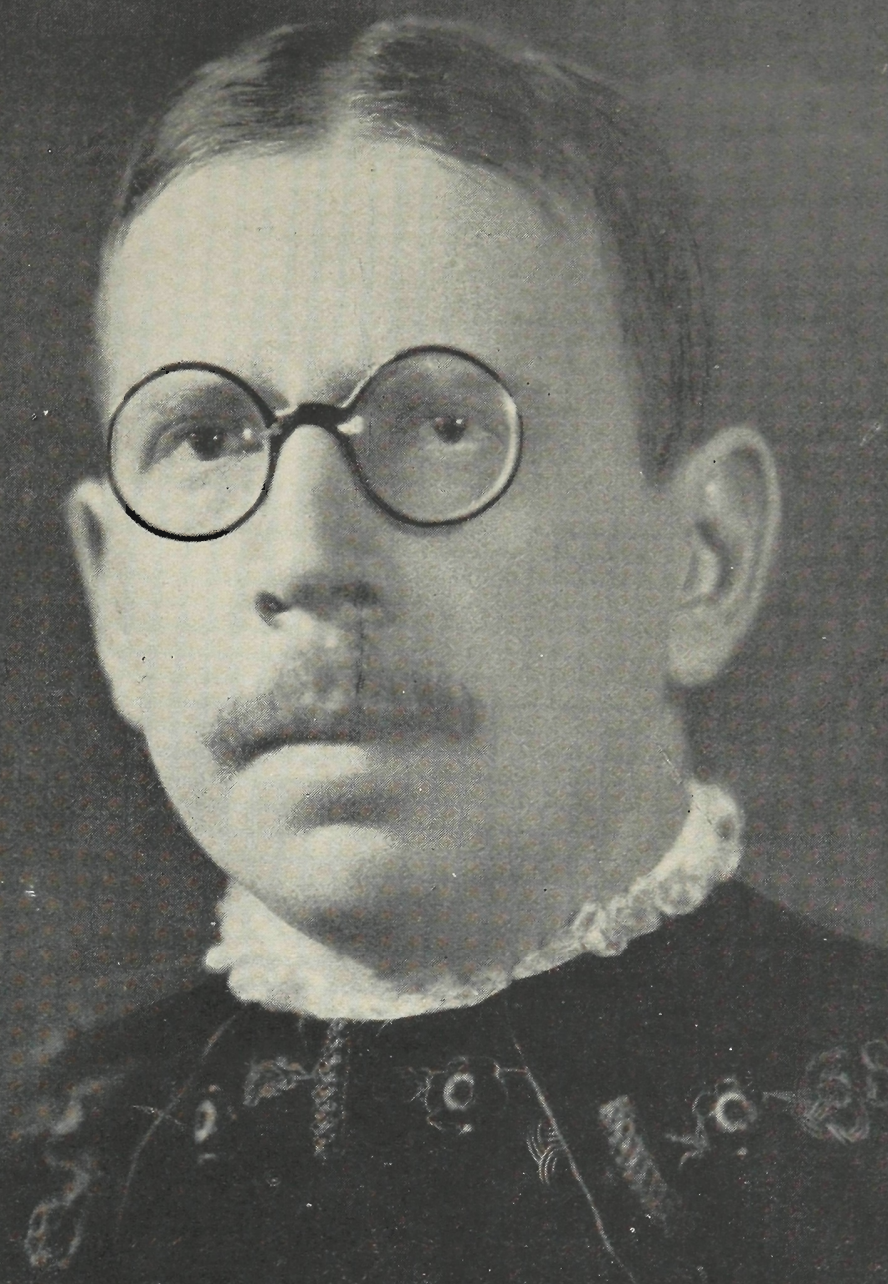

1.

ino 


\section{Professor Dr. José de Alcantara Machadó d'Oliveira}

Com profunda emoção e indizivel mágua a Faculdåde de Direito de S. Paulo viu ocorrer, a $10^{\circ}$ de abril último, o folecimento do professor dr. José de Alcântara Machado D'Oliveira.

O professor AxcÂNTARa MACHado deixou neşta casa uma saudade que jamais se dissipará. Todos lamentamos, do fundo da alma, a perda de tẫo querỉdo amigo, que representava, para os seus colegas, um companheiro de qualidades modelares e, para os seus discípuluson um guia espiritual dos mais provectos.

$\mathrm{Na}$ esteira de saudade que nos ficou após o seu passamento, avulta, reverente, a nossa admiração pelas virtudes que integravam a sua personalidade e pela fecunda materia lização que tiveram durante a sua vida de professor. e de cidadão.

A Faculdade de Direito encontra-se inclinada ainda à beira do túmulo do pranteado Mestre. A comoção confrange-a. Não lhe perturba, porém, a firmeza do pronunciamento, com que enaltece a extraordinária contribuição prestada ao seu patrimônio de glórias seculares por esse seu inolvidavel filho. ALCÂNTARa Machado soube dignificar esta casa como professor notavel e, tambem, pelo seu civismo ativo e pelo muito amor que dedicou à nossa terra.

Por vezes o distanciaram da cátedra as investiduras políticas, a que era chamado pela sua peculiar capacidade de bem servir à coletividade, sem alardes, mas com arraigado devotamento. Ainda assim, entretanto, continuava sempre a dar lustre à Faculdade de Direito, como expoente magnífico 
que era da nossa cultura jurídica, em quem o saber se revestia do aço do mais puro carater, e engrandecer a Escola onde plasmara a sua mentalidade $\mathrm{e}$ onde os seus méritos o haviam destacado a plasmar, por igual modo, a mentalidade das novas gerações.

Natural de Piracicaba, onde nasceu a 19 de-autubro de 1875, o professor Alcântara Machado era filho do professor dr. Brasillo Augusto Machado p'Oliveira (Barão de Brásílio Machado) e de dona Maria Leopoldina de Sousa Machado d'Oliveira. Fez os seus primeiros estudos na Escola Neutralidade, dirigida por JoÃo KoPKE, e iniciou os seus preparatórios no ano de 1887. Em 1890, matriculou-se na Faculdade de Direito, onde, após um curso brilhante, concluiu os seus estudos em 1893, sendo logo depois nomeado lente substituto da Faculdade e substituto da sexta secção, em 1895. Recebeu gráu de doutor aos vinte anos de idade. Em 1915, foi declarado professor substituto da cadeira então denominada de Medicina Pública. Em 1925, passou a catedrático de Medicina Legal, tomando posse da cadeira em substituição ao professor Amâncio de Carvalho. Em 1927, foi nomeado vice-diretor da Faculdade, tendo exercido o cargo de diretor no período de 1931 a 1935, quando tiveram início as grandes refórmas pelas quais vái passando o prédio deste estabelecimento.

O professor Alcântara Machado era membro fundador e presidente da Sociedade de Medicina Legal e Criminologia de S. Paulo. Fez parte da comissão encarregada de elaborar o projeto do Código do Processo Civil e Comercial do Estado de S. Paulo. Na política, iniciou a sua carreira como vereador à Camara Municipal de S. Paulo, função em que permaneceu de 1911 a 1916. Em 1915 foi eleito, pelo Partido Republicano Paulista, deputado estadual. De 1926 a 1930, exerceu o cargo de senador estadual.

No Congresso do Estado, inúmeras foram as suas iniciativas de realce, como, por exemplo, a do projeto de lei que criava o Manicômio Judiciário. A regulamentação da pro- 
fissão de engenheiro, de que tảmbem se ocupou, valeu-lhe o título de membro honorário do Instituto de Engenharia de S. Paulo.

Sempre se recorda, com entusiasmo, o fervor cívico com que o professor Alcântara Machado se colocou a serviço de S. Paulo na revolução de 1932, figurando entre os mais ardorosos defensores da causa constitucionalista.

Representou o seu Estado na Assembléia Nacional Constituinte de 1933, em cujo cenáculo liderou a representação de S. Paulo. Promulgada a Constituição de 1934, foi representante de S. Paulo no Senado Federal.

Em todos esses postos deixou traços inesqueciveis da sua passagem, em realizações a que destinava o melhor dos seus esforços.

Foi ainda presidente da Faculdade Paulista de Filosofia e Letras, que fundou em 1931; presidente do Conselho Superior da Escola de Política e Sociologia; membro do Instituto Histórico e Geográfico Brasileiro e membro do Conselho Penitenciário do Estado.

Dentre os trabalhos que publicou, destacam-se os seguintes: "Do momento da formação dos contratos por correspondência" (1892); "A embriaguez e a responsabilidade criminal" (1893); "O hipnotismo" (1895); "A deformidade nas lesões pessoais" (1891); "Suicídios na capital de S. Paulo" (1905); "Problemas municipais"; "Os honorários médicos", cuja segunda edição foi publicada em 1922; "Vida e morte do Bandeirante" (1929); "O exame pericial no Direito Romano"; "O ensino na perícia"; "Brasílio Machado" (1938).

A mais recente de suas obras é o projeto de Código Criminal que elaborou a convite do Governo da República. Em outubro de 1934, o professor dr. VicENTE Ráo, ministro da Justiça, em nome do Govêrno, solicitou ao professor Alcântara Machado que se incumbisse da elaboração de um projeto que atualizasse e completasse a nossa legislação criminal. Pouco depois, todavia, em fevereiro de 1935, pro- 
punha-se na Câmara dos Deputados fosse convertido em leí o projeto Virgílio de Sá Pereira, com as modificações que lhe haviam sido feitas pela sub-comissão legislativa de que faziam parte, com o autor do projeto, Evaristo de Morais e Búlhões Pedreira. A' vista dos estudos que se realizavam para a possivel conversão do projeto Sá Pereira em lei, preferiu o professor AlcÂntara Machado, ao invés de se entregar à tarefa da organização de um novo projeto, colaborar, como membro e presidente da Comissão de Constituição e Justiça do Senado, na revisão daquele trabalho, logo que foi remetido àquela casa do Congresso, e o fez em companhia dos senadores Artur Costa, Clodomir Cardozo, Edgard Arruda e Pagheco de Oliveira, funcionando como assistente técnico o professor Candido Mota Filho. Havia o professor Alcântara Machado ultimado a revisão dos capítulos que lhe haviam tocado, quando se operou a mudança do regime em novembro de 1937 . No mês seguinte, o professor dr. Francisco Campos, ministro da Justiça, pediu-lhe que se encarregasse da elaboração do novo Código Penal.

O labor exaustivo a que se entregou o professor AlcÂNTARA Machado produziu esplêndido fruto. A parte geral do seu ante-projeto, publicada meses depois com a respectiva exposição de motivos, causou a melhor impressão, pelas diretrizes progressistas em que se norteava e pela excelência da redação. Prosseguiu com infatiagvel atividade, e pouco tempo depois deu a lume a parte especial, recebida com iguais louvores. A crítica construtiva que se fez a essa excelente produção jurídica foi examinada, pelo autor do projeto, com superior acolhimento, e ele próprio o apresentou, após, em nova redação, em que mais o aperfeiçoara.

O projeto Alcântara Machado, com as modificações que lhe foram feitas pela comissão revisora constituida dos eminentes juristas Nelson Hungria, Vieira Braga, Narcélio de Queiroz e Roberto LirA, à qual prestou tambem a sua colaboração o sr. ministro Costa E Silva veiu a constituir o novo Código Penal do Brasil, a vigorar no vindouro mês de ja- 
neiro. Representa um dos mais expressivos títulos de glória: do pranteado Mestre desta casa. A sua elaboração ele dedicou uma energia singular, trabalhando com afinco, de corpo e alma. Não poupou, no desempenho desse encargo ingente, a própria saude.

Fulgurante escritor, Alcântara Machado era membro da Academia Brasileira e da Academia Paulista de Letras, da qual foi presidente. $O$ discurso de recepção com que $o$ saudou Arânro Perxoto, a 20 de maio de 1933, constituiu uma feliz apreciação da personalidade do digno filho e herdeiro de Brasílio Machado, continuador admiravel do pai. A "Vida e morte do Bandeirante", observava Afrânio Peixoto, era o grande livro do recipiendário, na sua carinhosa evocação de S. Paulo do passado, na sua arguta e impressiva fixação de aspectos da história colonial do Brasil. E a alocução de Alcântara Machado, peça magistral em que esplendiam o talento e a finura do homem de letras, deu-lhe oportunidade para mais uma vez demonstrar o seu amor à terra que o viu nascer.

"Assim, - disse - nem por gracejo se lembraria alguem de pôr em dúvida o meu brasileirismo. Paulista sou, ha quatrocentos anos. Prendem-me ao chão de Piratininga todas as fibras do coração, todos os imperativos raciais. A mesa em que trabalho, a tribuna que ocupo nas escolas, nos tribunais, nas asesmbléias políticas deitam raizes, como o leito de Ulisses, nas camadas mais profundas do solo, em que dormem para sempre os mortos de que venho. A fala provinciana, que me embalou no berço, descansada e cantada, espero ouví-la ao despedir-me do mundo, nas orações da agonia. Só em minha terra, de minha terra, para minha terra tenho vivido; e, incapaz de serví-la quanto devo, prezo-me de amá-la quanto posso.

“Amo-a com a ingenuidade e a cegueira inseparaveis do verdadeiro amor. Em sua paizagem tranquila. Em sua gente menos sobranceira do que retraida. Pelas qualidades que lhe constroem a grandeza. Pela dignidade com que su- 
porta a desgraça. Preocupada com as coisas essenciais. Idealista e prática, mercê da fusão harmoniosa das almas de Marta e Maria. Ávida dos bens materiais, porque tem horror à dependência; mas î̉gualmente ambiciosa das riquezas impereciveis; e por isso mesmo tão ufana de suas fábricas e lavouras, como de suas escolas e de seus poetas. Faminta de progresso e respeitosa da tradição: a algumas braças dos cafesais de S. José do Rio Pardo, o rancho de Euclides; junto às chaminés de Campinas, a mansão das andorinhas; ao pé dos arranha-céus de S. Paulo, a árvore das lágrimas. A tal ponto generosa e "benéfica aos forasteiros", que se um deles chega, cheio de sanhas e de prevenções, logo se esquece de combatê-la e se põe a cortejá-la escandalosamente. Tenaz como a verdade. Paciente como a justiça. E, como a claridade, leal".

A Faculdade de Direito de S. Paulo orgulha-se de haver tido entre os seus Mestres esse paulista benemérito, cujo desaparecimento é motivo de infinito pesar, para todos quantos palpitam pelos ideais que foram a razão suprema da sua existência. 